Int. J. Electrochem. Sci., 11 (2016) 6266 - 6278

International Journal of

ELECTROCHEMICAL

SCIENCE

www.electrochemsci.org

\title{
Application of a Disposable Doxorubicin Sensor for Direct Determination of Clinical Drug Concentration in Patient Blood
}

\author{
Anlin Peng ${ }^{1,2}$, Huilin $\mathrm{Xu}^{3}$, Caikui Luo ${ }^{2 *}$,Hong Ding ${ }^{1, *}$ \\ ${ }^{1}$ Department of Pharmacy, Wuhan University, Wuhan 430072, China \\ ${ }^{2}$ Department of Pharmacy Wuhan No.3 Hospital, Wuhan 430072, China \\ ${ }^{3}$ Department of Pharmacy Wuhan No.5 Hospital, Wuhan 430072, China \\ *E-mail: 912692441@qq.com, ckack@126.com \\ *Corresponding authors: Prof. Hong Ding and Caikui Luo
}

doi: $10.20964 / 2016.07 .38$

Received: 21 March 2016 / Accepted: 2 May 2016 / Published: 4 June 2016

\begin{abstract}
A novel simple method for direct detection of clinical drug doxorubicin (DOX) was developed by the disposable sensor. The MWNTs/Polt-L-lysine modified screen printed electrode (SPE) was fabricated to monitor the DOX pharmacokinetic in clinical blood samples. The electrochemical behavior of DOX was observed at MWNTs/Polt-L-lysine SPE by cyclic voltammetry (CV) and square wave voltammetry (SWV). The electrochemical oxidation peak current was greatly increased because of nanocomposites. Under optimized conditions, the oxidation peak current of DOX measured by SWV exhibited a good linear property with the increasing of the concentration in the range of $0.0025 \mu \mathrm{M}$ to $0.25 \mu \mathrm{M}$. The detection limit was founded to be $1.0 \mathrm{nM}$. Furthermore, the disposable DOX SPE was successfully used to monitor the clinical DOX pharmacokinetic with good results. The DOX concentration-time curve was also obtained by the established method. The developed DOX sensor could be successful to monitor the therapeutic drug for clinical individualized treatment.
\end{abstract}

Keywords: disposable sensor; doxorubicin; modified screen printed electrode; clinical sample determination

\section{FULL TEXT}

(C) 2016 The Authors. Published by ESG (www.electrochemsci.org). This article is an open access article distributed under the terms and conditions of the Creative Commons Attribution license (http://creativecommons.org/licenses/by/4.0/). 